\title{
morosoopy tophy
}

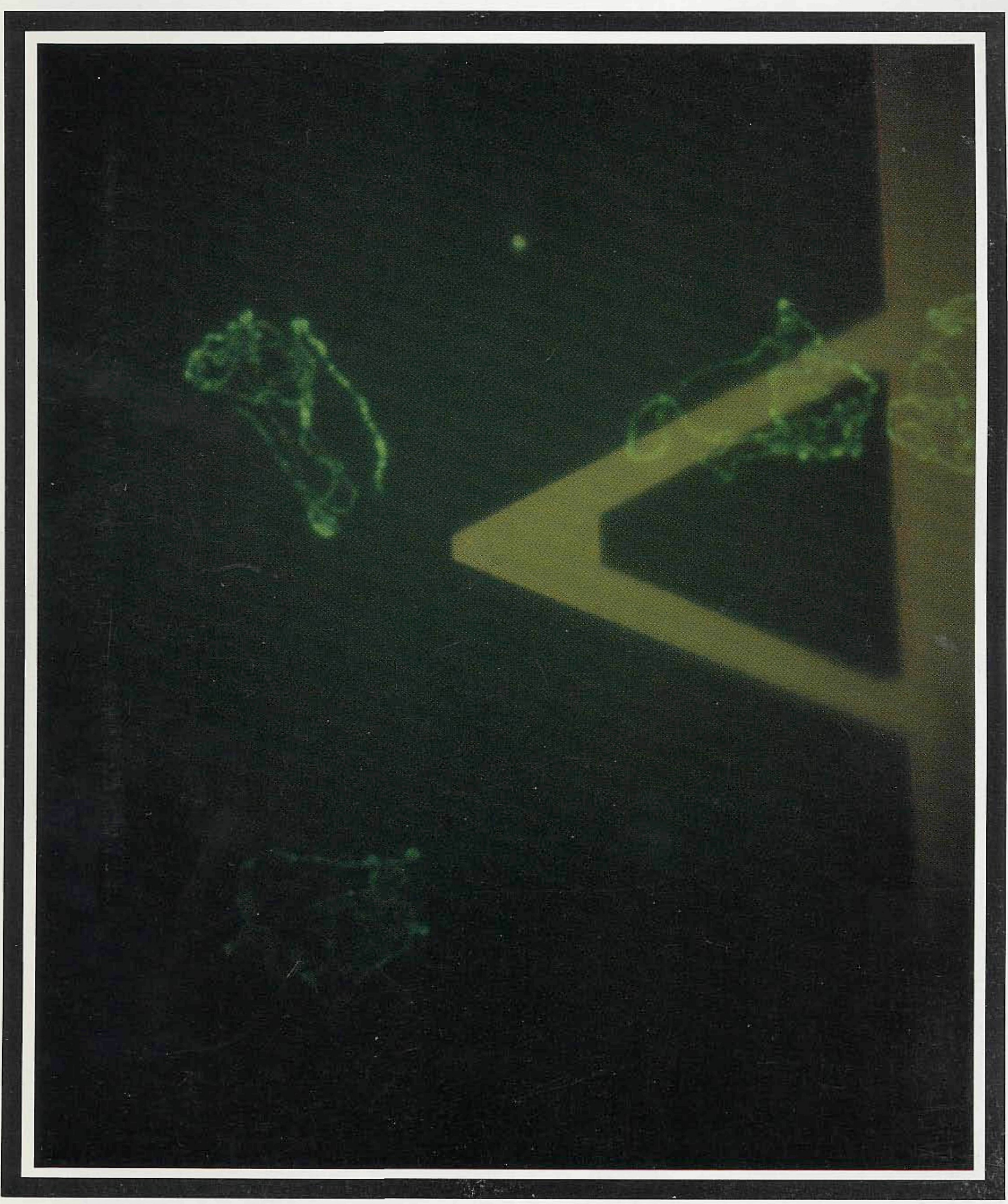


The first compute-controlled SEM below $\$ 50,000$.

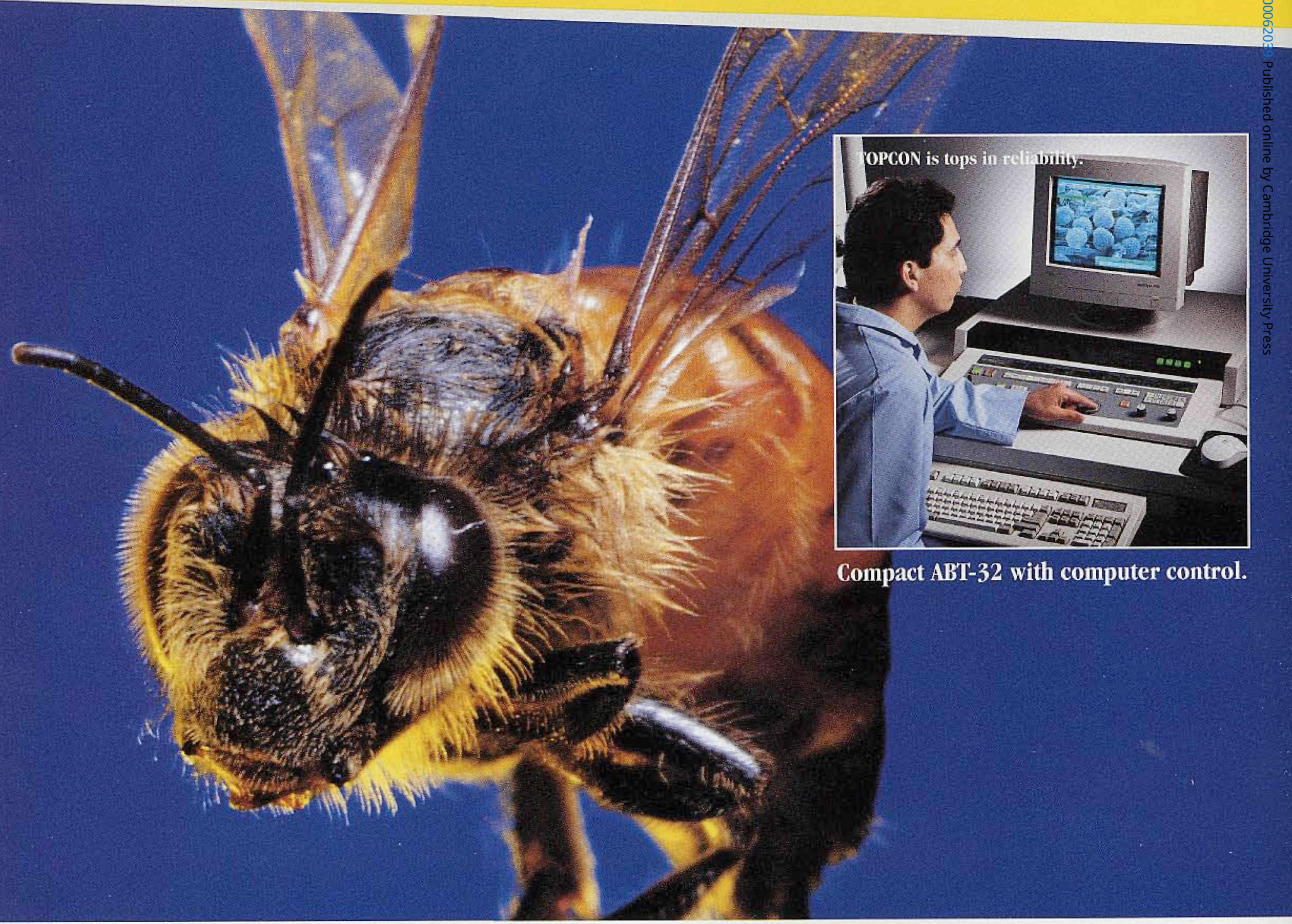

\section{Don't get stung buying SEMs.}

We challenge you to find better value anywhere than Topcon.

From the under $\$ 50,000$ ABT-32 to the versatile SM-720, every TOPCON SEM offers more features, capabilities and ease-of-use for the money.

TOPCON SEMs provide all the important computer benefits: Windows ${ }^{\odot}$ environment. Bright, clear ty-rate images. Frame averaging, up to 128 frames. Image processing, $2048 \mathrm{x}$ 2048 resolution. Image and SEM setup file archiving.
Then there are the dual controls. Computer or SEM console. We left the manual controls in place for reliability. But we know a lot of people still like to twist those knobs!

\section{New 10 Year Warranty!}

Look all you want for SEMs. But don't stop until you've seen TOPCON. For product specifications and full warranty information, call us at 800-538-6850. Or write: TOPCON Technologies 6940 Koll Center Parkway, Pleasanton, CA 94566 USA.

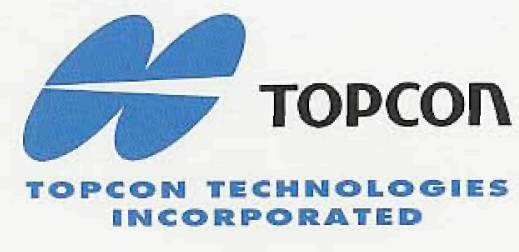




\section{An IMPORTANT Note to ALL Readery}

Our interest is to send this newsletter only to those who wish a copy. and then to an address which allows delivery. A "?" following your name on the address of this issue indicates that we do not know if you wish to continue to receive the newsletter - or even if you are receiving this issue.

Should you be a U.S. reader in this category, and wish to continue to receive the newsletter at no cost, please complete the questionnaire in the postage-paid reply card later in this issue.

Should you be an international (including Canadian) reader in this category, with a "?" following your name, and wish to receive a no cost copy subscription to the newsletter, you might just return the name/address from the envelope of this issue by mail - or advise us by Fax. Please do not use elail for this purpose.

And, while you are at it, we would be most pleased if you would advise us of others in your organization who would like a subscription. We would like to increase our readership - particularly on an international basis.

\section{I}

\section{A Not So IMPORTANT Note to ALReadery}

To be of value, to you as a reader and to we as publishers, the "material" content of this newsletter must be of interest and value to our readership. I ask you to help in this effort by submitting articles.

The criteria for topics is only that they should be of interest to a reasonable number of microscopists. As you consider the material in this issue, we would like to have more in the way of advances in, and approaches to, any aspect of the broad technology - and some with a bit of humor or other "lighter" interest.

You could send contributions by mail, Fax or eMail. We, in return, would return a draft copy for proofing. We try to keep articles in 1/4 page "chunks". A $1 / 4$ page, with header, contains some 400 words and each additional $1 / 4$ page contains some 500 words. We try to keep articles to a full page (1,900 words) in length and shorter articles are also appreciated.

Should your material contain illustrations or images (color $\mathrm{OK}$ ), we lose some 100 words for each vertical inch of half page column.
I

\section{A Note to Our New International Readers}

This monthly newsletter, now starting it's third year of publication, has previously been sent at no charge to some 11,000 microscopists in North America. With this issue, our first in full color, we are starting sending no charge copies overseas.

This issue is being sent to several thousand microscopists in 16 countries and we intend to substantially increase our international readership in the future. In addition to microscopists in North America and Europe, we particularly wish to gain readership other areas. To this end, we hope that current international readers will introduce the newsletter to their associates - users and manufacturers alike.

The objective of this publication, perhaps unlike any other, is to publish material and information of interest and value to a very broad range of microscopists. Clearly as a "newsletter, we try to cover any and all topics of interest to a reasonable number of microscopists. We have no intent to try to publish a "high technology" journal. And, while we need advertising income to provide free copies, we have no interest in becoming an "advertising catalog".

While we do not submit that the quality of material in this issue is all that great, it is substantially better than that in our earlier issues. Jean-Paul Revel (CALTECH) and R.M. (Bob) Fisher (Univ. of Washington), plus the good folks at McCrone Associates, continue to assist in the development of the newsletter. We hope that others, including our new overseas readers, will assist in making the publication truly of value.

International readers will note a considerable amount of material in this issue of local (North American) interest. In 1994, as we expand our international readership, we intend to break out North American news and other material in a separate 4-page insert. This will leave us with a basic monthly newsletter more suitable for international interests - and one where additional copies can be printed at very low cost. In the future we may develop additional inserts relating to the local interests of, and mailed with the basic newsletter to, microscopists in other "areas".

Our immediate interest, however, is to develop the newsletter into a publication of real value to the microscopy community. Your help in making this newsletter interesting would be appreciated!

-. Don Grimes, Editor

\section{Front Cover Image}

The cover photo was taken through an inverted optical microscope and shows fluorescently labeled polytene chromosomes acquired from a Drosophila salivary gland and absorbed to a glass slide. The Atomic Force Microscope (AFM) cantilever of the TopoMetrix Explorer ${ }^{T M}$ LifeSciences Scanning Probe Microscope is clearly visible. Positioning of the AFM tip within the desired cluster of chromosomes is greatly facilitated by the inverted optical microscope.

With the Exploer LifeSciences SPM, imaging is possible in any of the full continuum of scanning modes including contact, lateral force, modulated force and non-contact. Because this sample was imaged in a liquid environment, meniscus forces were eliminate and scanning involved far lower forces than imaging in air would have required. For further information, contact TopoMetrix, (408)982-9700.

\section{mICROSCOPY TODAY}

A montiy newsletter dedicated to the unique interests in microscopy of, and published at no cost to, some 14,500 microscopists worldwide.

PO Box 620122, Middleton, WI 53562 - Tel.: (608)836-1970 - Fax: (608)836-1969 - eMail: 74250.331@COMPUSERVE.COM Copyright in 1994 by Today Enterprises, All rights reserved

Don Grimes, Editor 
